\title{
Involvement of Spermidine in the Reduced Lifespan of Caenorhabditis elegans During Vitamin $B_{12}$ Deficiency
}

\author{
Tomohiro Bito ${ }^{1, *\left(\mathbb{D}, \text { Naho Okamoto }^{2}, \text { Kenji Otsuka }^{1} \text {, Yukinori Yabuta }\right.}{ }^{1}{ }^{\mathbb{D}}$, Jiro Arima ${ }^{1}$, \\ Tsuyoshi Kawano ${ }^{1}$ and Fumio Watanabe ${ }^{1}$ \\ 1 Department of Agricultural, Life and Environmental Sciences, Faculty of Agriculture, Tottori University, \\ Tottori 680-8553, Japan; cobalamin1985@yahoo.co.jp (K.O.); yabuta@tottori-u.ac.jp (Y.Y.); \\ arima@tottori-u.ac.jp (J.A.); kawano@tottori-u.ac.jp (T.K.); watanabe@tottori-u.ac.jp (F.W.) \\ 2 The United Graduate School of Agricultural Sciences, Tottori University, Tottori 680-8553, Japan; \\ d18a2005y@edu.tottori-u.ac.jp \\ * Correspondence: bito@tottori-u.ac.jp; Tel.: +81-857-31-5443
}

Received: 27 August 2019; Accepted: 18 September 2019; Published: 19 September 2019

\begin{abstract}
Vitamin $\mathrm{B}_{12}$ deficiency leads to various symptoms such as neuropathy, growth retardation, and infertility. Vitamin $B_{12}$ functions as a coenzyme for two enzymes involved in amino acid metabolisms. However, there is limited information available on whether amino acid disorders caused by vitamin $B_{12}$ deficiency induce such symptoms. First, free amino acid levels were determined in vitamin $\mathrm{B}_{12}$-deficient Caenorhabditis elegans to clarify the mechanisms underlying the symptoms caused by vitamin $B_{12}$ deficiency. Various amino acids (valine, leucine, isoleucine, methionine, and cystathionine, among others) metabolized by vitamin $\mathrm{B}_{12}$-dependent enzymes were found to be significantly changed during conditions of $\mathrm{B}_{12}$ deficiency, which indirectly affected certain amino acids metabolized by vitamin $B_{12}$-independent enzymes. For example, ornithine was significantly increased during vitamin $\mathrm{B}_{12}$ deficiency, which also significantly increased arginase activity. The accumulation of ornithine during vitamin $\mathrm{B}_{12}$ deficiency constitutes the first report. In addition, the biosynthesis of spermidine from ornithine was significantly decreased during vitamin $B_{12}$ deficiency, likely due to the reduction of $S$-adenosylmethionine as a substrate for $S$-adenosylmethionine decarboxylase, which catalyzes the formation of spermidine. Moreover, vitamin $\mathrm{B}_{12}$ deficiency also demonstrated a significant reduction in worm lifespan, which was partially recovered by the addition of spermidine. Collectively, our findings suggest that decreased spermidine is one factor responsible for reduced lifespan in vitamin $\mathrm{B}_{12}$-deficient worms.
\end{abstract}

Keywords: arginase; Caenorhabditis elegans; ornithine; spermidine; vitamin $\mathrm{B}_{12}$

\section{Introduction}

Vitamin $\mathrm{B}_{12}\left(\mathrm{~B}_{12}\right)$, commonly known as the red-colored vitamin, has the largest molecular mass and the most complex structure of all vitamins. $\mathrm{B}_{12}$ is only synthesized by certain bacteria and is primarily concentrated in higher predatory organisms in the food chain. Thus, animal-derived foods such as meat, milk, and fish are good sources of $B_{12}$ [1]. Plant-derived foods such as vegetables and fruits contain no or trace amounts of $B_{12}$ because plants do not require $B_{12}$ for growth. Therefore, strict vegetarians are at a greater risk of developing $\mathrm{B}_{12}$ deficiency than nonvegetarians [2]. People with atrophic gastritis who develop low stomach acid output easily present the food protein-bound $B_{12}$ malabsorption, which prevails in elderly people. Thus, strict vegetarians and elderly people are at an increased risk of developing $B_{12}$ deficiency. In case of hereditary $B_{12}$ deficiency, the patients defect transport proteins (intrinsic factor, a transcobalamin II, and R-binder) and the factors regarding the 
intracellular processing of $\mathrm{B}_{12}$ participating in absorption, blood transport, and intracellular metabolism of $\mathrm{B}_{12}$ [3].

$\mathrm{B}_{12}$ is converted into two coenzyme forms in living cells, namely, $5^{\prime}$-deoxyadenosylcobalamin and methylcobalamin, which function as coenzymes for methylmalonyl-CoA mutase (MCM, EC 5.4.99.2) [4] and methionine synthase (MS, EC 2.1.1.13) [5], respectively. MCM catalyzes the conversion of $R$-methylmalonyl-CoA to succinyl-CoA via the tricarboxylic acid (TCA) cycle in the catabolic pathways of branched-chain amino acids (valine, leucine, and isoleucine) and methionine. $\mathrm{B}_{12}$ deficiency leads to the excess accumulation of methylmalonic acid (MMA), which potently inhibits succinate dehydrogenase in the TCA and further leads to the disruption of normal glucose and glutamic acid metabolism [6]. MS is involved in the synthesis of methionine from homocysteine and $\mathrm{N}^{5^{\prime}}$-methyltetrahydrofolate, and the formed methionine is converted to $S$-adenosylmethionine (SAM), which is involved in cellular methylation reactions [7]. In addition, $\mathrm{B}_{12}$ deficiency reportedly results in significant increases in homocysteine, which induces oxidative damage in various cellular components. Accordingly, $\mathrm{B}_{12}$ deficiency can induce various diseases, such as megaloblastic anemia, developmental disorders, growth retardation, and neuropathy. However, the mechanisms involved remain poorly understood.

Results from our previous study indicated that Caenorhabditis elegans developed severe $\mathrm{B}_{12}$ deficiency associated with infertility, growth retardation, and reduced lifespan when grown under $B_{12}$-deficient conditions [8], suggesting that $C$. elegans may be a suitable model for understanding the physiological function of $B_{12}$ and the mechanisms underlying the symptoms caused by $B_{12}$ deficiency.

As described above, both $\mathrm{B}_{12}$-dependent MCM and MS function in the cellular metabolism of various amino acids. Indeed, $\mathrm{B}_{12}$ deficiency reportedly induces disorders of various amino acids metabolized in the $\mathrm{B}_{12}$-dependent pathway and indirectly affects amino acids metabolized in $\mathrm{B}_{12}$-independent pathways [9]. However, there is limited information available regarding whether such amino acid disorders induce these symptoms of $B_{12}$ deficiency.

In this study, we determined free amino acid levels in $B_{12}$-deficient $C$. elegans for clarifying the mechanisms underlying the symptoms caused by $\mathrm{B}_{12}$ deficiency. Therefore, ornithine was significantly increased in C. elegans during $B_{12}$ deficiency. Ornithine, a precursor compound of polyamines, is formed from arginine as an essential amino acid in worms [10]. While this process is catalyzed by arginase, $C$. elegans do not contain an intact urea cycle because no homologous genes involved in the urea cycle have been found (wormbase, wormbase.org, KEGG, and https://www.genome.jp/kegg/). However, in this study, we demonstrated that $B_{12}$ deficiency significantly increased arginase activity, leading to increased ornithine. Furthermore, the synthesis of spermidine from ornithine was significantly decreased during $B_{12}$ deficiency, which appears to be an important factor responsible for the reduced lifespan of $\mathrm{B}_{12}$-deficient worms.

\section{Materials and Methods}

\subsection{Organisms}

The N2 Bristol wild-type C. elegans strain was maintained at $20^{\circ} \mathrm{C}$ on nematode growth medium plates using the Escherichia coli OP50 strain as a food source [11]. $\mathrm{B}_{12}$-supplemented (control) and $\mathrm{B}_{12}$-deficient worms were prepared as described previously [8]. $B_{12}$-deficient worms were then transferred to $B_{12}$-supplemented medium for three generations and used as the recovery worms [8]. For evaluating the effects of $B_{12}$ deficiency on polyamine levels and the lifespan of the worms, we prepared control worms are grown in ornithine-supplemented (final concentration $10 \mu \mathrm{mol} / \mathrm{L}$ ) medium for three days and $B_{12}$-deficient worms grown in SAM-supplemented (final concentration $1 \mu \mathrm{mol} / \mathrm{L}$ ) medium for three days. 


\subsection{Preparation of a Homogenate of Worms}

Control, $\mathrm{B}_{12}$-deficient, and recovery worms ( $0.2 \mathrm{~g}$ wet weight each) were homogenized in 500 $\mu \mathrm{L}$ of $100 \mathrm{mmol} / \mathrm{L}$ potassium phosphate buffer ( $\mathrm{pH}$ 7.0) on ice using a hand homogenizer (AS ONE Corp., Osaka, Japan). The homogenates were centrifuged at $15,000 \times g$ for $10 \mathrm{~min}$ at $4{ }^{\circ} \mathrm{C}$, and these supernatants were used as crude enzymes or crude homogenates, except where otherwise noted.

\subsection{Determination of Free Amino Acids in Worm Bodies}

The homogenates of worms as described above were heated at $80{ }^{\circ} \mathrm{C}$ for $10 \mathrm{~min}$ and then centrifuged at $15,000 \times g$ for $10 \mathrm{~min}$ at $4{ }^{\circ} \mathrm{C}$, the supernatants (200 $\mu \mathrm{L}$ each) were added to 100 $\mu \mathrm{L}$ of $10 \%(v / v)$ trichloroacetic acid, mixed vigorously, and centrifuged at $10,000 \times g$ for $10 \mathrm{~min}$ at $4{ }^{\circ} \mathrm{C}$. Each supernatant $(250 \mu \mathrm{L})$ was diluted with an equal volume of $0.25 \mathrm{~mol} / \mathrm{L}$ lithium citrate buffer ( $\mathrm{pH}$ 2.2) (Wako Pure Chemical Industries, Osaka, Japan). The diluted solution, after being filtered with Millex ${ }^{\circledR}$-LH membrane filter (Merck Millipore, Darmstadt, Germany), was analyzed using a fully-automated amino acid analyzer (JEOL JLC-500/V, Nihon Denshi, Tokyo, Japan). The injection volume was $50 \mu \mathrm{L}$. Figure 1 indicates the outlines of the free amino acid analysis method. Supplementary Figure S1 shows the chromatograms of free amino acid analysis.

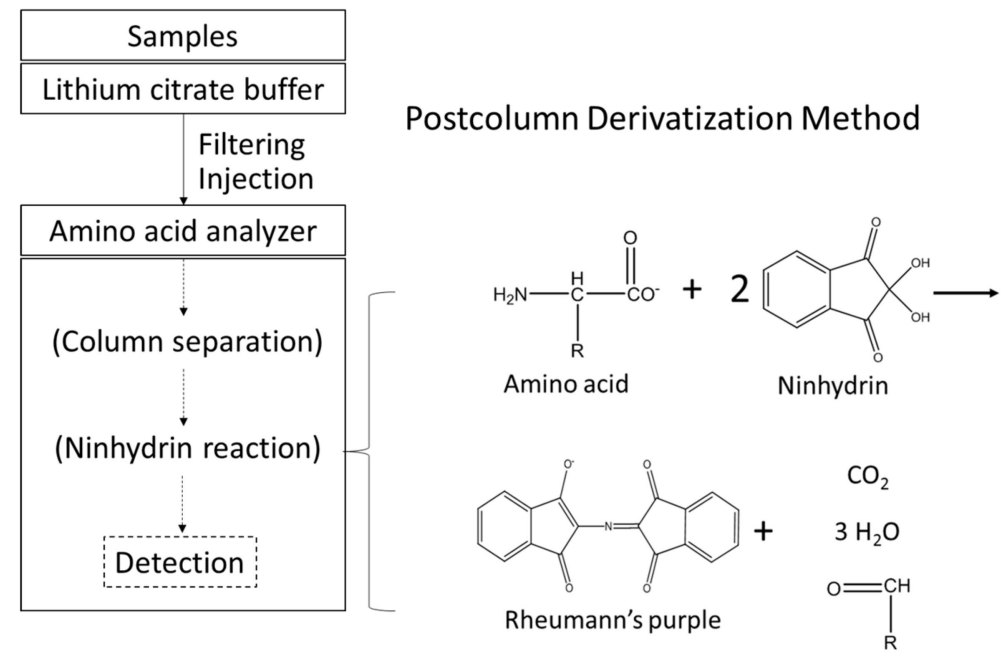

Figure 1. Outline of the amino acid analysis method.

\subsection{Enzyme Assays}

Ornithine decarboxylase (ODC) activity was assayed using high-performance liquid chromatography (HPLC) using a fluorescence derivatization method of putrescine (Put) [12]. In detail, worms (0.05 g) grown under control, $\mathrm{B}_{12}$ deficiency, recovery, ornithine-supplemented control, and SAM-supplemented $B_{12}$ deficiency conditions were homogenized in a $40 \mathrm{mmol} / \mathrm{L}$ sodium phosphate buffer ( $\mathrm{pH} 7.5)(200 \mu \mathrm{L})$ containing $0.1 \mathrm{mmol} / \mathrm{L}$ pyridoxal phosphate and $2 \mathrm{mmol} / \mathrm{L}$ dithiothreitol and centrifuged at $15,000 \times g$ for $10 \mathrm{~min}$ at $4{ }^{\circ} \mathrm{C}$. The supernatant fraction was then used as the crude enzyme. The reaction mixture $(250 \mu \mathrm{L})$ contained $50 \mathrm{mmol} / \mathrm{L}$ sodium phosphate buffer $(\mathrm{pH} 7.5)$, $0.15 \mathrm{mmol} / \mathrm{L}$ pyridoxal phosphate, $0.3 \mathrm{mmol} / \mathrm{L} \mathrm{L}$-ornithine, and $100 \mu \mathrm{L}$ of each crude enzyme. The enzymatic reaction was started with the addition of L-ornithine, incubated for an hour at $37^{\circ} \mathrm{C}$, and terminated with the addition of $50 \mu \mathrm{L}$ of $8 \%(v / v) \mathrm{HClO}_{4}$. The reaction mixture was then centrifuged at $15,000 \times g$ for $10 \mathrm{~min}$ at $4{ }^{\circ} \mathrm{C}$, and the supernatant was filtered with a Millex-LH membrane filter (Merck Millipore). An aliquot $(30 \mu \mathrm{L})$ of the filtrate was treated with $30 \mu \mathrm{L}$ of $50 \mu \mathrm{g} / \mathrm{mL}$ phthaldialdehyde regent (Sigma-Aldrich, Saint Louis, MO, USA) and $50 \mu \mathrm{L}$ of $10 \mathrm{mmol} / \mathrm{L}$ borate buffer (pH 9.5) and then incubated for $4 \mathrm{~min}$ at $25{ }^{\circ} \mathrm{C}$ to form a fluorescent derivative of putrescine (Put). The prepared sample $(20 \mu \mathrm{L})$ was then injected into a reverse-phase HPLC column (Wakosil-II 5C18HG, $\varphi 4.6 \times 250 \mathrm{~mm}$ ) 
that had been equilibrated with $80 \%$ methanol for $1 \mathrm{~h}$ at $25{ }^{\circ} \mathrm{C}$. Put was eluted with a linear gradient of methanol $80 \%(v / v)$ to $100 \%(v / v)$ at $0-11 \mathrm{~min}, 100 \%(v / v)$ at $11-14 \mathrm{~min}, 100 \%(v / v)$ to $80 \%(v / v)$ at $14-15 \mathrm{~min}$, and $80 \%(v / v) 15-20 \mathrm{~min})$ at a flow rate of $1 \mathrm{~mL} / \mathrm{min}$ at $25^{\circ} \mathrm{C}$. The fluorescent derivative was then determined with fixed excitation $(340 \mathrm{~nm})$ and emission $(455 \mathrm{~nm})$ wavelengths using a Shimadzu HPLC apparatus (SCL-10A VP system controller, DGU-20A3 degassing unit, LC-10Ai liquid chromatograph, and CTO-6A column oven) equipped with a fluorescence detector (RF-530, Shimadzu).

Arginase activity was assayed using an arginase assay kit (BioAssay Systems, CA, USA) according to the manufacturer's instructions. The absorbance at $430 \mathrm{~nm}$ that was changed by the enzyme reaction for $2 \mathrm{~h}$ was measured using a Sunrise Rainbow RC-R microplate reader (Tecan Austria GmbH, Salzburg, Austria). Arginase activity was then calculated with the calibration curve of urea as a standard. To obtain the optimum $\mathrm{pH}$ of worm arginase activity, various buffers ranging from $\mathrm{pH} 4.0$ to 10.0 (pH 4-6, $20 \mathrm{mmol} / \mathrm{L}$ acetate-sodium acetate buffer, pH 6-8 $20 \mathrm{mmol} / \mathrm{L}$ phosphate-sodium buffer, and pH 8-10 carbonate-sodium carbonate buffer) were used. Preliminary experiments indicated that the optimum temperature and $\mathrm{pH}$ of worm arginase was $30^{\circ} \mathrm{C}$ and $\mathrm{pH} 8.0$, respectively, and $\mathrm{MnSO}_{4}$ was required for enzyme activity (Supplementary Figure S2).

Regarding $\mathrm{N}^{\omega}$-hydroxy-L-arginine (NOHA) as a specific arginase inhibitor, $\mathrm{B}_{12}$-deficient worms were grown in $\mathrm{B}_{12}$-deficient medium containing NOHA (final concentration at $10 \mathrm{nM}$ ) for 3 days before the assay of arginase activity assay. The arginase inhibitor was used at a concentration shown to not influence the growth of the worms.

\subsection{Other Assays}

SAM and S-adenosylhomocysteine (SAH) were assayed by HPLC according to the modified method of Wang et al. [13]. Each worm (0.05 g wet weight) was homogenized in $200 \mu \mathrm{L}$ of $0.4 \mathrm{~mol} / \mathrm{L}$ $\mathrm{HClO}_{4}$ on ice. After centrifugation at $15,000 \times g$ for $15 \mathrm{~min}$ at $4{ }^{\circ} \mathrm{C}$, the supernatant was filtered through a Millex-LH membrane filter (Merck Millipore). Each prepared extract $(20 \mu \mathrm{L})$ was injected into the Shimadzu HPLC apparatus equipped with an SPD-10A VP UV/VIS detector (Shimadzu). The analytical method was developed with a flow rate of $1 \mathrm{~mL} / \mathrm{min}$, column temperature of $35^{\circ} \mathrm{C}$, and $\mathrm{UV}$ detection at $254 \mathrm{~nm}$. A Wakosil 5C18HG column $(\varphi 4.6 \times 250 \mathrm{~mm}$, Wako) was equilibrated with $80 \%$ solvent A (50 mmol/L NaH${ }_{2} \mathrm{PO}_{4}(\mathrm{pH} 3.0)$ containing $8 \mathrm{mmol} / \mathrm{L}$ octanesulfonic acid sodium salt) and $20 \%$ solvent B (methanol). SAM and SAH were eluted over a 13-min gradient as follows: $80 \%$ solvent A-20\% solvent B at 0 min to $3 \mathrm{~min}$, a liner gradient of $60 \%$ solvent A-40\% solvent B at 3 min to 9 min, and $60 \%$ solvent A-40\% solvent B at $9 \mathrm{~min}$ to $13 \mathrm{~min}$. As modification points, column and gradient conditions were changed as described above.

Polyamines, such as Put and Spermidine (Spd), were analyzed using a standard HPLC method [14]. Worms (0.05 g wet weight) grown under control, $\mathrm{B}_{12}$ deficiency, recovery, ornithine-supplemented control, and SAM-supplemented $B_{12}$ deficiency conditions were homogenized in $200 \mu \mathrm{L}$ of $0.3 \mathrm{~mol} / \mathrm{L}$ $\mathrm{HClO}_{4}$ using a hand homogenizer on ice. After centrifugation $\left(15,000 \times g\right.$, 10 min at $\left.4{ }^{\circ} \mathrm{C}\right)$, the supernatants were used as extracts. Polyamines were derivatized with benzoyl chloride, and the reaction mixture $(1110 \mu \mathrm{L})$ was mixed with $1 \mathrm{~mL}$ of $2 \mathrm{~mol} / \mathrm{L} \mathrm{NaOH}, 10 \mu \mathrm{L}$ of benzoyl chloride, and $100 \mu \mathrm{L}$ of extract and incubated for $40 \mathrm{~min}$ at room temperature $\left(25^{\circ} \mathrm{C}\right)$. The reaction was terminated with the addition of $2 \mathrm{~mL}$ of a saturated $\mathrm{NaCl}$ solution, and benzoylated polyamines were extracted with $2 \mathrm{~mL}$ of cold diethyl ether. After centrifugation $\left(1500 \times g, 5 \mathrm{~min}\right.$ at $\left.4{ }^{\circ} \mathrm{C}\right)$, an aliquot $(1 \mathrm{~mL})$ of diethyl ether was recovered, evaporated to dryness under a nitrogen flow, and dissolved in $200 \mu \mathrm{L}$ of 50\% (v/v) methanol. Authentic Put, Spd, and 1,6-diaminohexane were treated under the same conditions, and 1,6-diaminohexane was used as the internal standard. Each prepared extract was then filtered through a Millex-LH membrane filter (Merck Millipore) and injected into the Shimadzu HPLC apparatus equipped with a UV/VIS detector (Shimadzu). The analytical method was developed with a flow rate of $1 \mathrm{~mL} / \mathrm{min}$, column temperature of $35^{\circ} \mathrm{C}$, and UV detection at $254 \mathrm{~nm}$. A Wakosil-II 5 C18HG column $(\varphi 4.6 \times 250 \mathrm{~mm}$, Wako) was equilibrated with $50 \%$ methanol. Polyamines were eluted with a linear gradient of methanol $50 \%(v / v)$ to $55 \%(v / v)$ at $0-5 \mathrm{~min}, 55 \%(v / v)$ to $60 \%(v / v)$ at 
$5-20 \mathrm{~min}$, and $60 \%(v / v)$ to $80 \%(v / v)$ at $20-25 \mathrm{~min}$. Figure 2 shows the scheme of derivatization reaction of polyamines. Supplementary Figure S3 showed the chromatograms of polyamine analysis.

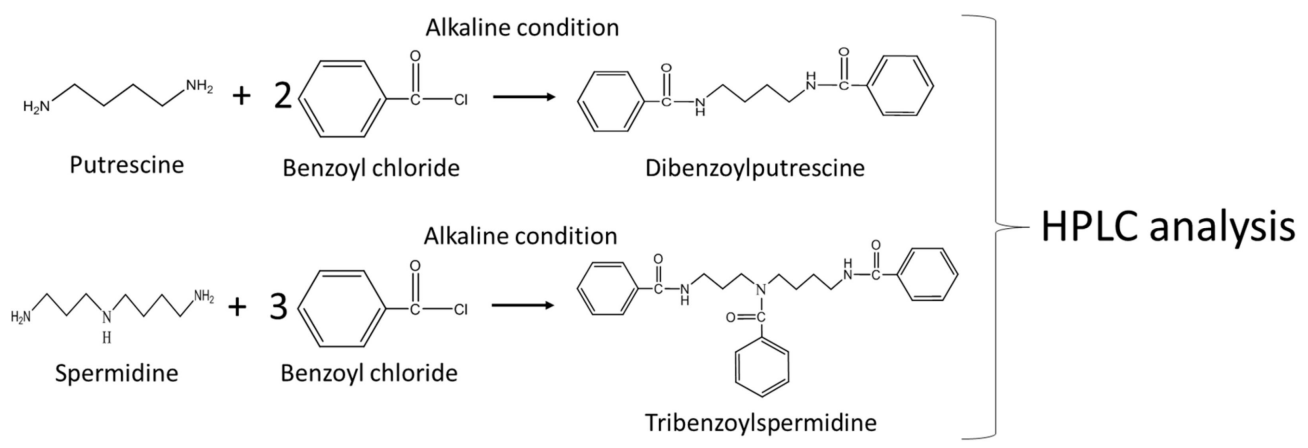

Figure 2. Scheme of derivatization of polyamines.

\subsection{Quantitative PCR Analysis}

Control worms were grown in ornithine (final concentration $10 \mu \mathrm{M}$ )-supplemented control medium for three days to evaluate the effects of accumulated ornithine on worm polyamine metabolism. $\mathrm{B}_{12}$-deficient worms were grown in SAM (final concentration $1 \mu \mathrm{M}$ )-supplemented $B_{12}$-deficient medium for three days to clarify the effects of added SAM on worm polyamine metabolism. Control worms, ornithine-supplemented control worms, $B_{12}$-deficient worms, and SAM-supplemented $\mathrm{B}_{12}$-deficient worms were used as samples in the following quantitative PCR analysis.

Total RNA was prepared from the worms using Sephasol ${ }^{\circledR}$-RNA1 (Nacalai Tesque, Kyoto, Japan). Total RNA was used to synthesize cDNA using the PrimeScript ${ }^{\mathrm{TM}}$ RT Reagent Kit with gDNA Eraser (Takara Bio, Shiga, Japan). Primer sets were designed using GENETYX software (GENETYX Corporation, Tokyo, Japan) as follows: ornithine decarboxylase (odc-1), forward primer sequence, 5'-AAGGGCTCGGATTCAAGATGGA-3',

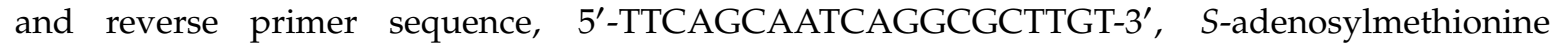
decarboxylase (smd-1), forward primer sequence, 5'-ATGCGAGCCGGTATTGACAAG-3', and reverse primer sequence, 5'-GGATGGTTGCGTATTGGTCAGT-3', spermidine synthase (spds-1), forward primer sequence, $5^{\prime}$-AACGGGATGAGTTCTCCTACCA-3' , and reverse primer sequence, 5'-ACTCGTGCTTCAAGACCTCTCT-3', human arginase type 1 erythroid. T21F4.1 was designed as follows: T21F4.1, forward primer sequence, $5^{\prime}$-CACGTGGGTGAGATAATATGCC-3' , and reverse primer sequence, 5'-CGTCGTCCGATACATTTCCTTC-3', $\beta$-actin (act-1 as an internal standard), forward primer sequence, $5^{\prime}$-TCCAAGAGAGGTATCCTTACCC-3' , and reverse primer sequence, 5'-CTCCATATCATCCCAGTTGGTG-3' . A CFX Connect ${ }^{\text {TM }}$ Real-Time System (Bio-Rad Laboratories, Inc. Hercules) with SYBR Premix Ex Taq (Takara Bio) was used to perform qPCR.

\subsection{Lifespan Analysis}

Control and $\mathrm{B}_{12}$-deficient worms were grown in ornithine (final concentration $10 \mu \mathrm{M}$ )-, SAM (final concentration $1 \mu \mathrm{M}$ )-, or Spd (final concentration $10 \mu \mathrm{M}$ )-supplemented (final concentration $10 \mu \mathrm{M}$ ) medium for three days to evaluate the effects of ornithine, SAM, and Spd on the lifespan of $C$. elegans. Control worms, ornithine-supplemented control worms, Spd-supplemented control worms, $B_{12}$-deficient worms, and Spd-supplemented $B_{12}$-deficient worms were used as samples in this experiment. The lifespan of the worms was measured by the method of Apfeld and Kenyon [15]. Each worm was picked (approximately 10 animals per plate) and allowed to grow at $20^{\circ} \mathrm{C}$ until they laid eggs. The next-generation worms (2- or 3-day-old) were picked to plates containing 5-fluoro-2'-deoxyuridine, which inhibits the worms from laying eggs. Worms were then tapped every $24 \mathrm{~h}$ and scored as dead when they did not move with repeated taps. The average lifespan of each worm was defined as a $50 \%$ survival rate obtained from the survival curves of each worm. 


\subsection{Protein Quantitation}

Protein quantification was determined by the Bradford method [16], with ovalbumin as the standard.

\subsection{Statistical Analysis}

All data were evaluated by one-way ANOVA (non-parametric test), and a post-hoc analysis was performed using Tukey's multiple comparison tests. Analyses were performed with GraphPad Prism 3 for Windows version 2.01 (GraphPad Software Inc., La Jolla, CA, USA). All data are presented as the mean \pm SEM. Differences were considered statistically significant at $p<0.05$.

\section{Results}

\subsection{Effect of $B_{12}$ Deficiency on Free Amino Acids in C. elegans}

Table 1 shows the effect of $B_{12}$ deficiency on free amino acids in C. elegans. Various amino acids (such as valine, leucine, and isoleucine) metabolized as part of the TCA cycle via the $\mathrm{B}_{12}$-dependent MCM pathway were increased significantly during $B_{12}$ deficiency because MCM activity was significantly decreased during $B_{12}$ deficiency [9]. Decreased MS activity induced a significant decrease in methionine, with a concomitant significant increase in cystathionine. In addition, threonine, lysine, aminoadipic acid, and ornithine levels were significantly increased during $B_{12}$ deficiency. Significantly changed levels of such amino acids were mostly recovered to control levels when $\mathrm{B}_{12}$-deficient worms were grown for three generations under $\mathrm{B}_{12}$-supplemented conditions (recovery). These results indicate that $B_{12}$ deficiency induces metabolic disorders of various amino acids in $C$. elegans. However, the accumulation of ornithine during $B_{12}$ deficiency, to the best of our knowledge, is the first report.

Table 1. Concentrations of free amino acids and other compounds in C. elegans.

\begin{tabular}{cccc}
\hline & \multicolumn{3}{c}{ C. elegans (mmol/g wet weight) } \\
\cline { 2 - 4 } & Control & B $_{12}$ Deficiency & Recovery \\
\hline Amino acids & & & \\
\hline Aspatic acid & $1.29 \pm 0.22$ & $0.58 \pm 0.22$ & $1.37 \pm 0.29$ \\
Threonine & $0.55 \pm 0.04$ & $0.80 \pm 0.10^{*}$ & $0.49 \pm 0.08$ \\
Serine & $0.76 \pm 0.07$ & $0.93 \pm 0.17$ & $0.82 \pm 0.08$ \\
Asparagine & $0.57 \pm 0.07$ & $0.41 \pm 0.07$ & $0.61 \pm 0.05$ \\
Glutamic acid & $3.27 \pm 0.38$ & $3.41 \pm 0.28$ & $3.32 \pm 0.45$ \\
Glutamine & $1.32 \pm 0.22$ & $1.28 \pm 0.29$ & $1.27 \pm 0.15$ \\
Glycine & $0.73 \pm 0.06$ & $0.78 \pm 0.05$ & $0.63 \pm 0.11$ \\
Alanine & $5.80 \pm 0.66$ & $6.05 \pm 0.22$ & $5.53 \pm 0.39$ \\
Valine & $0.58 \pm 0.06$ & $1.03 \pm 0.13 *$ & $0.52 \pm 0.09$ \\
Methionine & $0.19 \pm 0.03$ & $0.12 \pm 0.03 *$ & $0.22 \pm 0.04$ \\
Isoleucine & $0.37 \pm 0.05$ & $0.61 \pm 0.08 *$ & $0.36 \pm 0.05$ \\
Leucine & $0.70 \pm 0.09$ & $1.07 \pm 0.12 *$ & $0.63 \pm 0.10$ \\
Tyrosine & $0.22 \pm 0.02$ & $0.30 \pm 0.02$ & $0.24 \pm 0.04$ \\
Phenylalanine & $0.35 \pm 0.05$ & $0.47 \pm 0.10$ & $0.40 \pm 0.06$ \\
Ornithine & $0.21 \pm 0.07$ & $0.43 \pm 0.05 *$ & $0.29 \pm 0.10$ \\
Lysine & $0.43 \pm 0.04$ & $0.71 \pm 0.01 *$ & $0.40 \pm 0.04$ \\
Histidine & $0.34 \pm 0.04$ & $0.55 \pm 0.12$ & $0.39 \pm 0.05$ \\
Arginine & $0.88 \pm 0.10$ & $1.14 \pm 0.16$ & $0.81 \pm 0.05$ \\
Hydroxyproline & $0.07 \pm 0.06$ & $0.03 \pm 0.01$ & $0.05 \pm 0.03$ \\
\hline Others & & & \\
\hline Cystathionine & $0.57 \pm 0.06$ & $3.57 \pm 0.31 *$ & $0.78 \pm 0.13$ \\
Aminoadipic acid & $0.79 \pm 0.09$ & $1.44 \pm 0.12 *$ & $0.92 \pm 0.15$ \\
Urea & $1.66 \pm 0.52$ & $2.44 \pm 0.90$ & $1.84 \pm 0.66$ \\
\hline
\end{tabular}


3.2. Effects of $B_{12}$ Deficiency on Arginase Activity and the Levels of mRNAs Encoding Putative Arginase in $C$. elegans

Ornithine is formed from arginine by the action of arginase involved in the urea cycle. However, C. elegans do not have an intact urea cycle. When we checked into the wormbase database, T21F4.1 [17] was registered as the orthologous gene human arginase type 1 and 2 erythroid variants in the wormbase database. Sequence analysis showed that $C$. elegans T21F4.1 has $27-35 \%$ and $68-73 \%$ of sequence identity and similarity, respectively, with homo sapiens, Bacillus caldovelox, Bacillus subtilis, and Rattus norvegicus arginases (Figure 3).

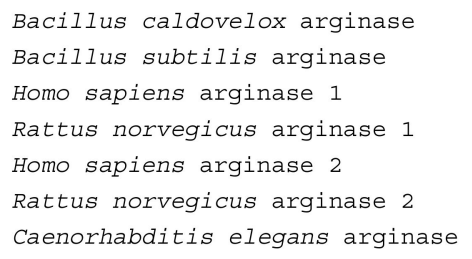

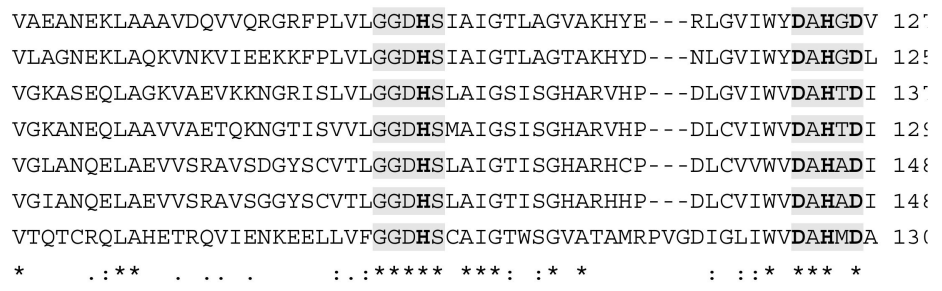

NTAETSPSGNIHGMPLAASLGFGHPALTQIGGY - - SPKIKPEHVVLIGVRSLDEGEKKF 18 NTLETSPSGNI HGMPLAVSLGIGHESLVNLEGY---APKIKPENVVIIGARSLDEGERKY 18: NTPLTTTSGNLHGQPVSFLLKELKGKI PDVPGFSWVTPCISAKDIVYIGLRDVDPGEHYI 19 NTPLTTSSGNLHGQPVAFLLKELKGKFPDVPGFSWVTPCISAKDIVYIGLRDVDPGEHYI 18 ! NTPLTTSSGNLHGQPVSFLLRELQDKVPQLPGFSWIKPCISSASIVYIGLRDVDPPEHFI $20 \varepsilon$ NTPLTTVSGNIHGQPLSFLIRELQDKVPQLPGFSWIKPCLSPPNLVYIGLRDVEPAEHFI $20 \varepsilon$ HTPDTSDTGNIHGMPVAHLLGFGDKTLVKIGDR---LPKLLPHNLCMVGIRDYESAEQEL $18^{\text {r }}$

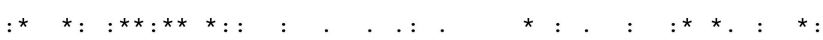

IREKGIKIYTMHEVDRLGMTRVMEETIAYLKERTDG-VHLSLDLDGLDPSDAPGVGTPVI 24: IKESGMKVYTMHEIDRLGMTKVIEETLDYLSACDG - -VHLSLDLDGLDPNDAPGVGTPVV 24 ( LKTLGIKYFSMTEVDRLGIGKVMEETLSYLLGRKKRPIHLSFDVDGLDPSFTPATGTPVV $25^{\circ}$ IKTLGIKYFSMTEVDKLGIGKVMEETFSYLLGRKKRPIHLSFDVDGLDPVFTPATGTPVV $24 ؛$ LKNYDIQYFSMRDIDRLGIQKVMERTFDLLIGKRQRPIHLSFDIDAFDPTLAPATGTPVV $26 \varepsilon$ LKSFDIQYFSMRDIDRLGIQKVMEQTFDRLIGKRKRPIHLSFDIDAFDPKLAPATGTPVV $26 \varepsilon$ LEKLGVRIFYAHEVEKRGIQDVMQEAQ-YLVTRNTIGYGLSIDLDGFDVSYAPAVGTPSA $24 \mathrm{\epsilon}$

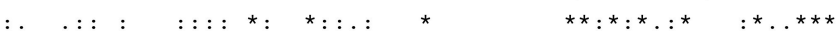

GGLTYRESHLAMEMLAEAQIITSAEFVEVNPILDER----NKTASVAVALMGSLFGEKLM 29 ؛ GGISYRESHLAMEMLYDAGIITSAEFVEVNPILDHK- - - NKTGKTAVELVESLLGKKLL $29 \ell$ GGLTYREGLYITEEIYKTGLLSGLDIMEVNPSLGKTPEEVTRTVNTAVAITLACFGLARE $31^{\circ}$ GGLSYREGLYITEEIYKTGLLSGLDIMEVNPTLGKTPEEVTRTVNTAVALTLSCFGTKRE 30 ؛ GGLTYREGMYIAEEIHNTGLLSALDLVEVNPQLATSEEEAKTTANLAVDVIASSFGQTRE 32\{ GGLTYREGLYITEEIHSTGLLSALDLVEVNPHLATSEEEAKATASLAVDVIASSFGQTRE $32 \varepsilon$ DGINALEFIKALLTIDLT-KLIATEIVEFLPRFDDTQRTSEQLVSSLVEYIYKTKQFQIN 30 !

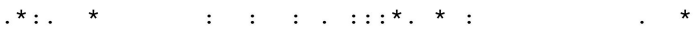

Figure 3. Amino acid sequence alignments of arginases and putative arginase T21F4.1 in C. elegans using CLUSTAL W. Alignment of C. elegans T21F4.1 (accession no.NP_001257027.2) with Bacillus caldovelox arginase (accession no. S68863), Bacillus subtilis arginase (accession no. NP_391912.1), Homo sapiens arginase 1 (accession no. NP_001231367.1), Rattus norvegicus arginase 1 (accession no. NP_058830.2), Homo sapiens arginase 2 (accession no. NP_001163.1), and Rattus norvegicus arginase 2 (accession no. NP_062041.1). Highlighted areas indicate the amino acid signature motifs characteristic of the arginase family. Residues in bold are critical for the formation of a bimetallic cluster at the active-site. The analysis reveals that C. elegans $\mathrm{T} 21 \mathrm{~F} 4.1$ has $27-35 \%$ and $68-73 \%$ of sequence identity and similarity, respectively, with other arginases. The $\mathrm{N}$ - and C-terminal residues are omitted for clarity.

To investigate the cause of ornithine accumulation caused by $\mathrm{B}_{12}$ deficiency, arginase activity was assayed. Worm arginase activity increased by approximately 1.7 -fold in the $\mathrm{B}_{12}$-deficient worms compared with the control worms (Figure $4 \mathrm{a}$ ). The increased arginase activity in $\mathrm{B}_{12}$-deficient worms was recovered to control levels when the $\mathrm{B}_{12}$-deficient worms were grown under-recovery and 
NOHA-treated (a potent inhibitor of arginase) conditions. These results suggested that ornithine accumulated by the increased arginase activity observed during $\mathrm{B}_{12}$ deficiency.

(a)

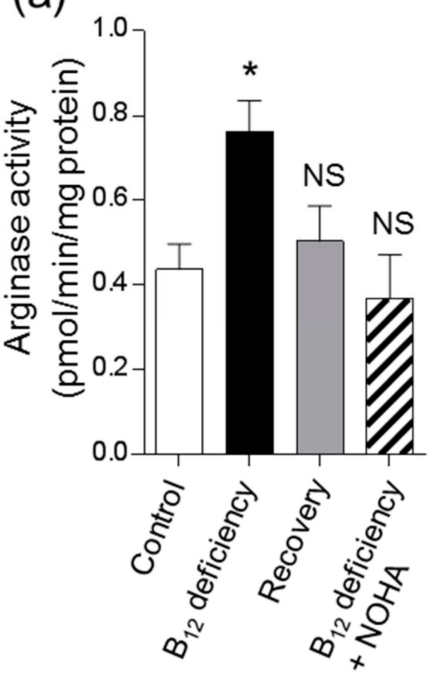

(b)

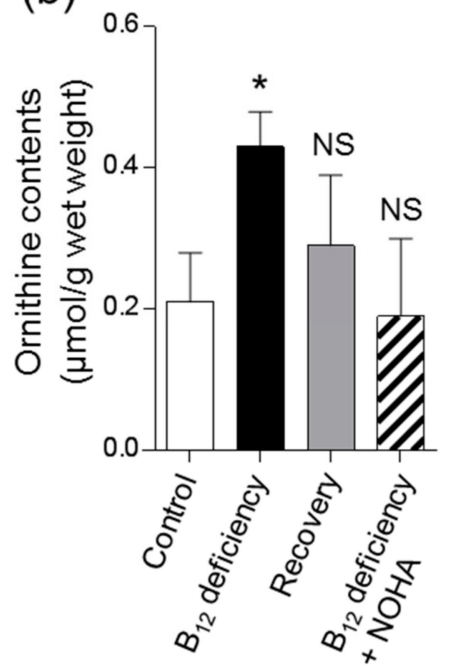

(c)

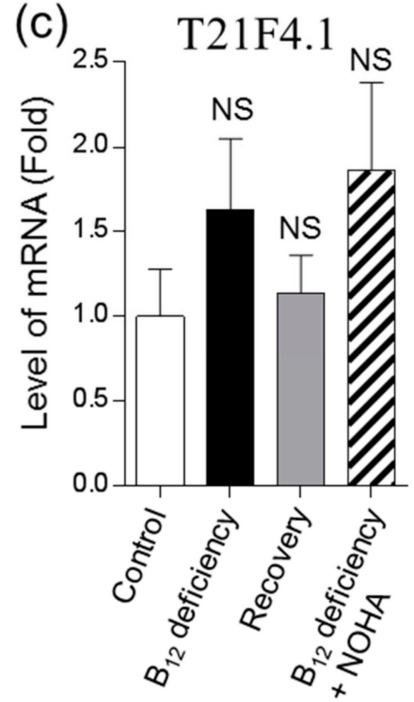

Figure 4. Effects of vitamin $B_{12}$ deficiency on arginase activity and the mRNA expression of the arginase orthologous gene, T21F4.1, in C. elegans. Arginase activity (a), ornithine contents (b), and mRNA expression levels of arginase orthologous gene, T21F4.1, (c) were determined in $\mathrm{B}_{12}$-deficient and control worms. After $\mathrm{B}_{12}$-deficient worms were grown for three generations under $\mathrm{B}_{12}$-supplemented conditions, these values were determined in the $\mathrm{B}_{12}$-treated worms (shown as "Recovery"). After $\mathrm{B}_{12}$-deficient worms were treated with $\mathrm{N}^{\omega}$-hydroxy-L-arginine (NOHA) as a potent inhibitor of arginase, these values were determined (shown as " $\mathrm{B}_{12}$ deficiency $+\mathrm{NOHA}$ "). Data represent the mean \pm SEM of three independent experiments. ${ }^{*} p<0.05$ versus Control group. NS represents no significant differences.

The mRNA expression level of T21F4.1 was noted to exhibit the tendency to increase in the $\mathrm{B}_{12}$-deficient worms (Figure 4c). However, this increased mRNA expression was not found to be significant. Nonetheless, T21F4.1 mRNA expression in $\mathrm{B}_{12}$-deficient worms was recovered to control levels when $\mathrm{B}_{12}$-deficient worms were grown under-recovery conditions. When $\mathrm{B}_{12}$-deficient worms were treated with NOHA, the addition of NOHA did not affect the mRNA expression level of T21F4.1, but did significantly decrease arginase activity, leading to decreased worm ornithine contents (Figure $4 a, b$ ). These results suggested that $B_{12}$ deficiency significantly increased arginase activity, which may be attributable to the mRNA expression of T21F4.1, leading to increased ornithine.

\subsection{Effect of $B_{12}$ Deficiency on Polyamine Levels of C. elegans}

$B_{12}$ deficiency showed that worm SAH increased significantly with a decrease in SAM (Figure $\left.5 a, b\right)$. The SAM/SAH ratio as an index of the cellular methylation reaction was decreased to approximately $39 \%$ of the control levels (Figure $5 \mathrm{c}$ ). The decreased SAM/SAH ratio was completely recovered to control levels when $B_{12}$-deficient worms were grown for three generations under $B_{12}$-supplemented conditions. These results indicate that $\mathrm{B}_{12}$ deficiency leads to a disorder of cellular methylation reactions in C. elegans as well as in mammals. 
(a)

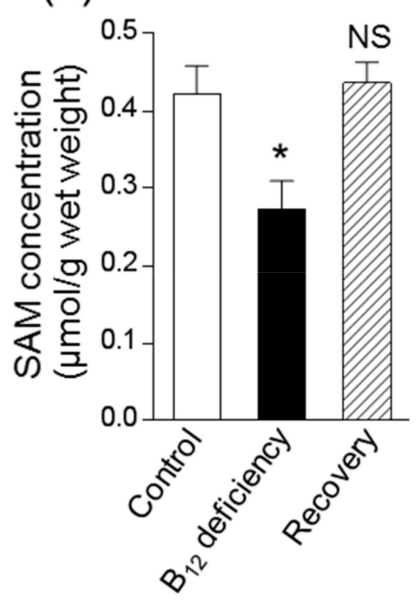

(b)

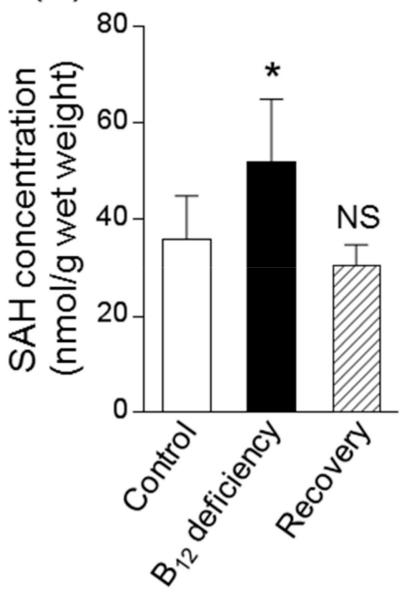

(c)

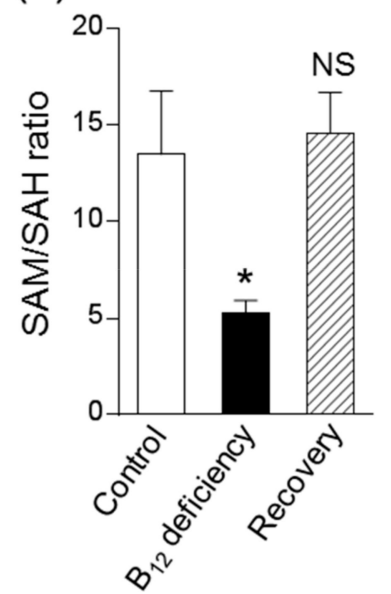

Figure 5. Effects of vitamin $B_{12}$ deficiency on S-adenosylmethionine and S-adenosylhomocysteine contents of $C$. elegans. S-Adenosylmethionine (SAM, a) and S-adenosylhomocysteine (SAH, b) were determined in $\mathrm{B}_{12}$-deficient and control worms using HPLC, and then the SAM/SAH ratio (c) was calculated. After $\mathrm{B}_{12}$-deficient worms were grown for three generations under $\mathrm{B}_{12}$-supplemented conditions, these values were determined in the $\mathrm{B}_{12}$-treated worms (shown as "Recovery"). Data represent the mean \pm SEM of three independent experiments. ${ }^{*} p<0.05$ versus Control group. NS represents no significant differences.

As shown in Figure 5a,b, $\mathrm{B}_{12}$ deficiency did not affect cellular Put but did significantly decrease Spd, which was approximately $83 \%$ of that in control worms. To clarify why Spd significantly decreased in C. elegans during $B_{12}$ deficiency, the mRNA expression of enzymes involved in the biosynthesis of polyamines from ornithine was determined. Remarkably, the enzyme activity and mRNA expression levels of ODC (Figure $6 c$,d) were increased in C. elegans during $B_{12}$ deficiency. This did not affect the mRNA levels of Spd synthase (SPDS, spds-1), but did lead to significantly decreased SAM decarboxylase (SAMDC) (smd-1) mRNA levels (Figure 6e,f). These altered mRNA levels were recovered to control levels when $\mathrm{B}_{12}$-deficient worms were grown for three generations under $\mathrm{B}_{12}$-supplemented conditions.

The addition of ornithine $(10 \mu \mathrm{M})$ to control worms significantly increased ornithine levels up to approximately $0.58 \mu \mathrm{mol} / \mathrm{g}$ of worm, at which the ornithine levels were considered greater than those of $\mathrm{B}_{12}$-deficient worms. The added ornithine did not affect levels of Spd content, ODC activity, or odc-1 and smd-1 mRNA expression levels (Figure $6 \mathrm{~b}-\mathrm{e}$ ). However, these levels that were changed during $\mathrm{B}_{12}$ deficiency were mostly recovered to control levels in SAM $(1 \mu \mathrm{M})$-treated $\mathrm{B}_{12}$-deficient worms (Figure $6 \mathrm{~b}-\mathrm{e}$ ). These results suggested that the decreased Spd in $\mathrm{B}_{12}$-deficient worms was due to the reduction of SAM as a substrate for SAMDC. 
(a)

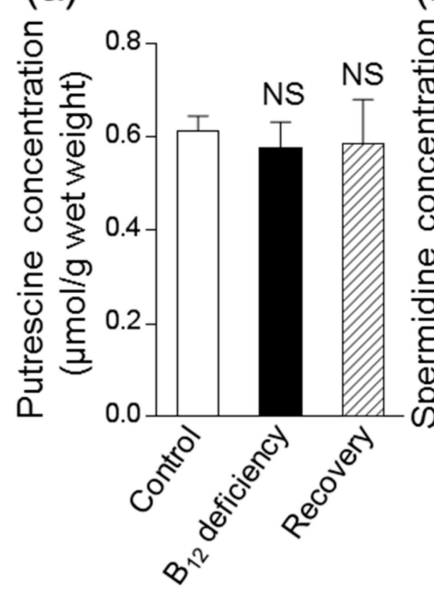

(d)

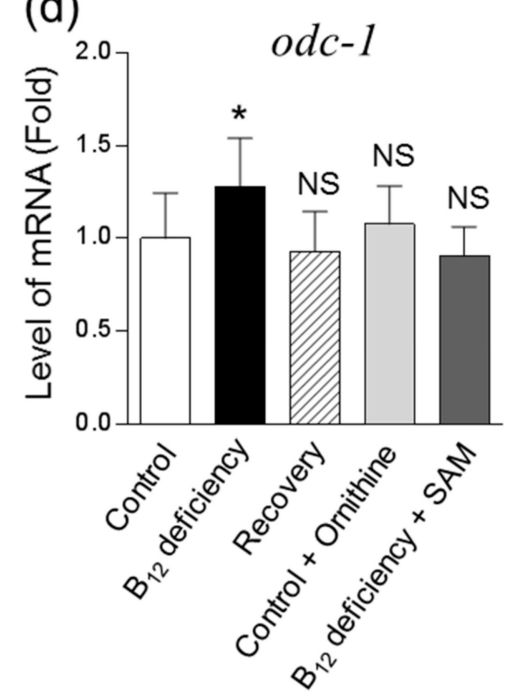

(b) (c)

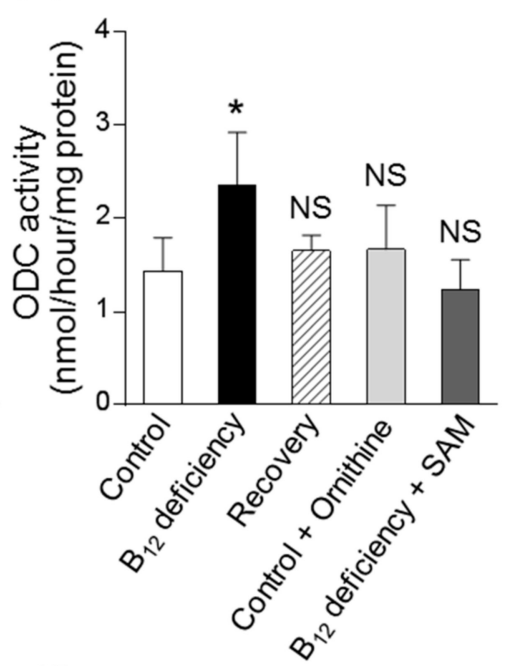

(f)

(e)

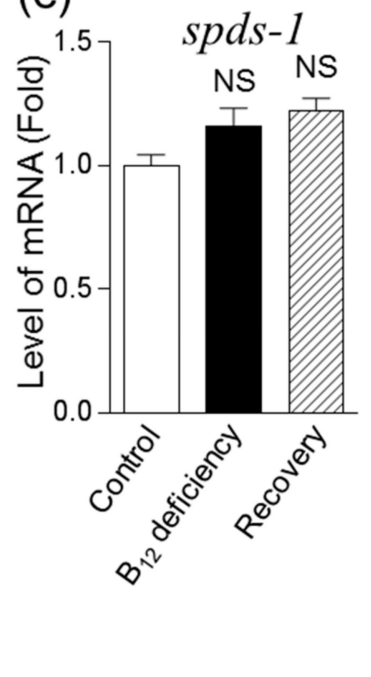

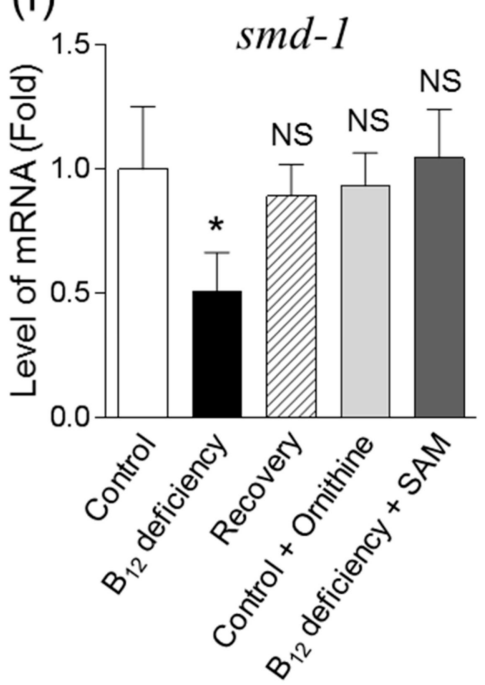

Figure 6. Effects of vitamin $B_{12}$ deficiency on polyamine (putrescine and spermidine) levels and the mRNA expression levels of genes encoding enzymes involved in the biosynthetic pathway of spermidine from ornithine in C. elegans. Putrescine (a) and spermidine (b) levels and ornithine decarboxylase $(\mathrm{ODC}, \mathrm{c})$ activity were determined in control and $\mathrm{B}_{12}$-deficient worms using HPLC. Control worms and $\mathrm{B}_{12}$-deficient worms were grown in ornithine (final concentration $10 \mu \mathrm{M}$ )-supplemented and S-adenosylmethionine (SAM) (final concentration $1 \mu \mathrm{M}$ )-supplemented medium for three days. Ornithine-supplemented control worms and SAM-supplemented $\mathrm{B}_{12}$-deficient worms were also analyzed and shown as Control + Ornithine and $\mathrm{B}_{12}$ deficiency + SAM, respectively. The mRNA expression levels of the orthologous genes of human ODC (odc-1), spermidine synthase (spds-1), and S-adenosylmethionine decarboxylase (smd-1) represent (d), (e), and (f), respectively. Data represent the mean \pm SEM of three independent experiments. ${ }^{*} p<0.05$ versus Control group. NS represents no significant differences.

\subsection{Effect of Supplementation of Spd on the Lifespan of C. elegans}

The maximal lifespan of $\mathrm{B}_{12}$-deficient worms was reduced to 22 days, compared with a lifespan of 28 days in control worms (Figure 7). The average lifespan was decreased to a greater extent in $\mathrm{B}_{12}$-deficient worms (15.48 days) than in control worms (20.84 days). When $\mathrm{B}_{12}$-deficient worms were treated with Spd, the average lifespan (15.48 days) was extended to 17.42 days (an increase up to 1.94 days) (Figure 7). In the case of control worms, the average lifespan of Spd-treated worms was 21.58 
days (an increase of only 0.74 days). The addition of $\mathrm{Spd}$ to $\mathrm{B}_{12}$-deficient worms showed a significantly extended average lifespan, compared with that of $\mathrm{B}_{12}$-deficient worms. However, no significant difference was noted between the average lifespan of $B_{12}$-deficient worms and Spd-treated $B_{12}$-deficient worms, considering the extended average lifespan of Spd-supplemented control worms. These results indicated that the reduced lifespan of $\mathrm{B}_{12}$-deficient worms was recovered by approximately $22.4 \%$ through the addition of Spd, suggesting that the reduced lifespan of worms during $B_{12}$ deficiency is partly caused by decreased Spd.

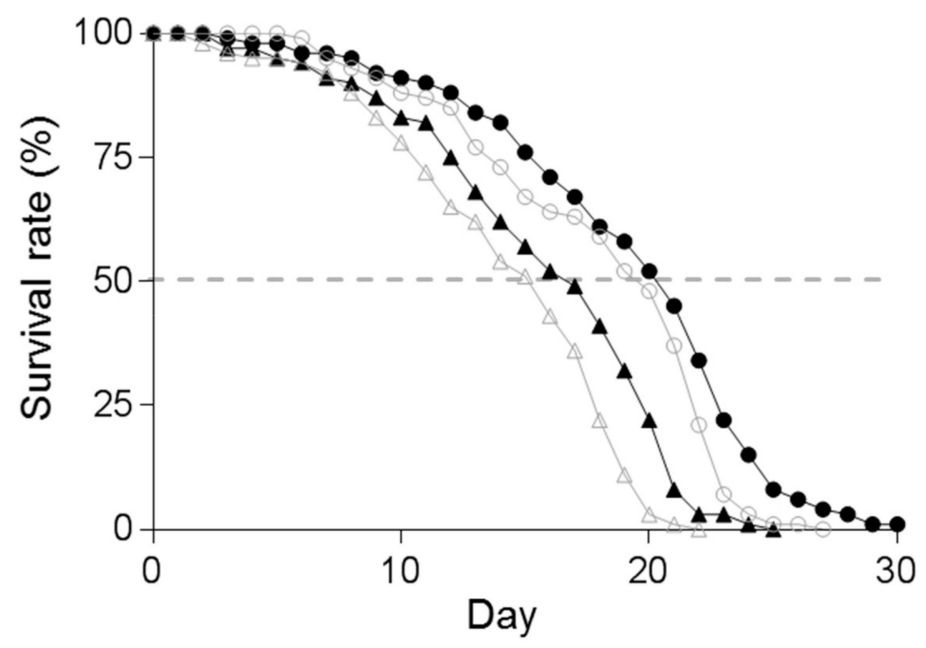

Figure 7. Effect of spermidine on lifespan in control and $\mathrm{B}_{12}$-deficient worms. Control worms $(\bigcirc), B_{12}$-deficient worms $(\triangle)$, control worms grown under the supplementation of spermidine $(\bullet)$, and $B_{12}$-deficient worms grown under the supplementation of spermidine $(\boldsymbol{\Lambda})$. The gray-colored graphs represent control and $\mathrm{B}_{12}$-deficient worm data in this Figure. The lifespan of worms (mean days, $n=$ number of worms scored) was measured as described in the text, control, 20.84 days, $n$ $=126, \mathrm{~B}_{12}$ deficiency, 15.48 days, $n=113$, spermidine-supplemented control, 21.58 days, $n=143$, spermidine-supplemented $\mathrm{B}_{12}$ deficiency, 17.42 days, $n=106$.

\section{Discussion}

$\mathrm{B}_{12}$ deficiency reportedly disrupts the TCA cycle due to the decreased activity of succinate dehydrogenase [6], which is inhibited by MMA accumulation observed during $B_{12}$ deficiency. This process then leads to significant increases in lysine and 2-aminoadipaic acid levels, with decreased formation of aspartic acid from oxaloacetic acid and glutamic acid through the actions of aspartate aminotransferase. Similarly, an increase was observed in the excretion of threonine, serine, valine, isoleucine, and lysine in urine in $\mathrm{B}_{12}$-deficient rats [5]. In addition, the mRNA and protein expression levels of hepatic serine dehydrogenase (a $B_{12}$-independent enzyme), which catalyzes the conversion of serine and threonine to pyruvate and 2-oxobutyrate, respectively, were significantly lowered in $B_{12}$-deficient rats [9]. However, the serine level was not found to be increased in $B_{12}$-deficient worms.

Furthermore, we demonstrated for the first time, to the best of our knowledge, that $B_{12}$ deficiency significantly increased the ornithine level, which is involved in polyamine biosynthesis [12]. The E. coli OP50 strain as the worm diet did not contain ornithine, and other amino acids showed no changes in E. coli cells grown in both $\mathrm{B}_{12}$-supplemented and $\mathrm{B}_{12}$-deficient conditions (data not shown). Ornithine is usually formed from arginine through the actions of arginase (EC 3.5.3.1), which is involved in the mammalian urea cycle [18]. However, C. elegans do not have an intact urea cycle because no homologous gene encoding enzymes involved in the urea cycle has been found in $C$. elegans (wormbase, wormbase.org, KEGG, www.genome.jp/kegg). Thus, C. elegans absolutely require arginine as an essential amino acid, as well as lysine, threonine, isoleucine, leucine, valine, methionine, phenylalanine, tryptophan, and histidine [10]. In particular, arginine reportedly functions as an energy-saving compound in C. elegans after being converted into arginine phosphate [10]. Arginine 
is not only metabolized by arginase to form ornithine and urea, but it is also metabolized by nitric oxide synthase (NOS) (EC 1. 14.13.39) to form nitric oxide (NO) and citrulline [19]. In this study, $\mathrm{B}_{12}$ deficiency did not affect arginine levels in C. elegans (Table 1), possibly to be able to sufficiently supply arginine from the diet. Although $B_{12}$ deficiency reportedly increased cellular NO levels in $C$. elegans [20], a full complement of homologs of NOS has not yet been identified in the genome of $C$. elegans, suggesting that NO produced by bacteria (in the diet) in the worm gut may diffuse into the tissues. Our previous study [20] indicated that $\mathrm{B}_{12}$-deficiency in worms induces severe oxidative stress, which likely stimulates arginase activity because oxidative species reportedly increase arginase activity in bovine aortic endothelial cells [21].

Remarkably, urea, which is formed from arginine by arginase, has a tendency to increase in $\mathrm{B}_{12}$-deficient $C$. elegans (Table 1 ). Similarly, urea has been reportedly excreted in C. elegans [22] and the other free-living nematode, Panagrellus redivivus [23], implying the occurrence of arginase in C. elegans. These observations suggest that ornithine is enzymatically synthesized by arginase from arginine in C. elegans as an essential amino acid. The amino acid disorders observed in C. elegans during $B_{12}$ deficiency are summarized in Figure 8.

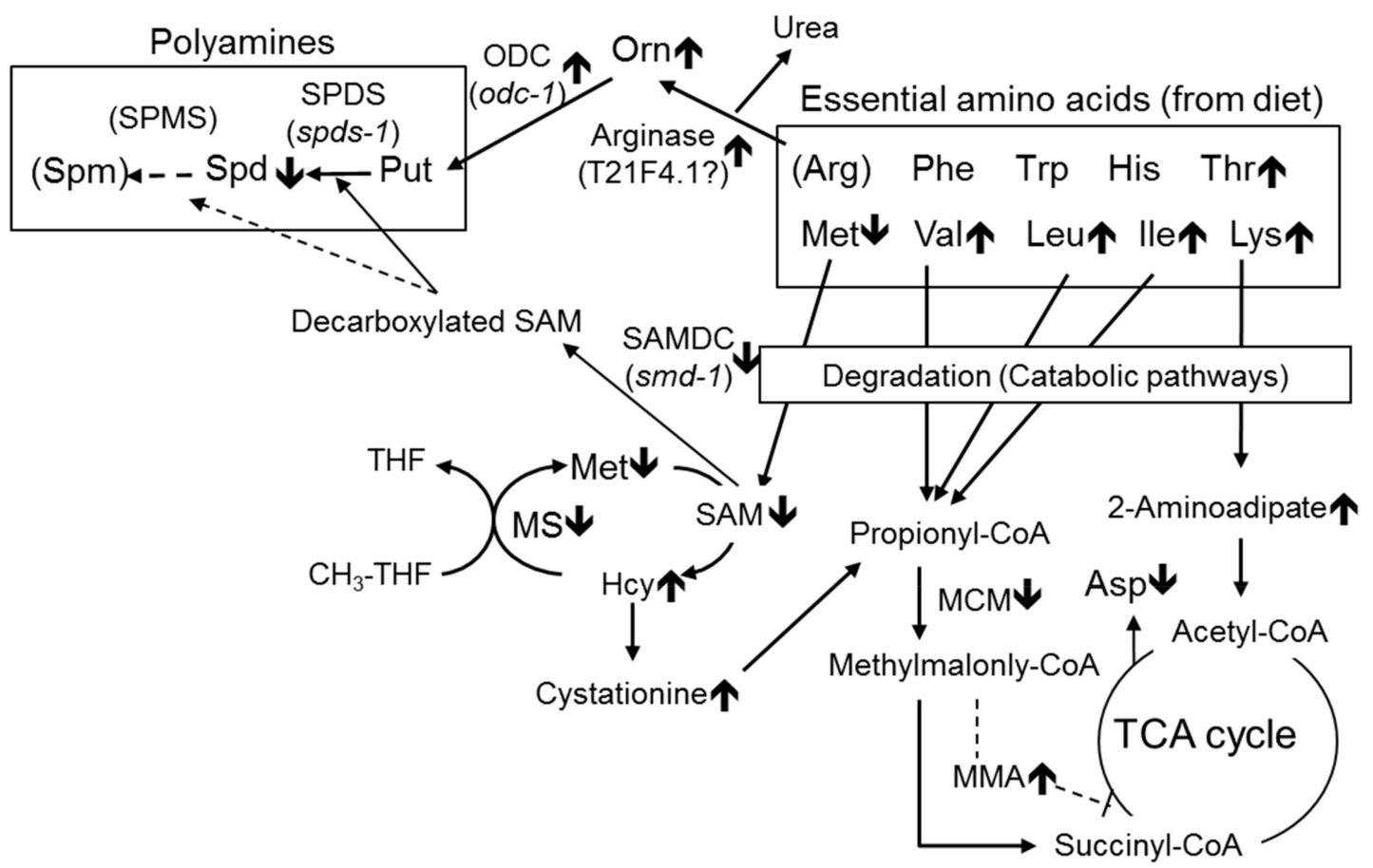

Figure 8. Summary of the metabolic disorders of amino acids observed in C. elegans during vitamin $\mathrm{B}_{12}$ deficiency. MCM, methylmalonyl-CoA mutase, MS, methionine synthase, MMA, methylmalonic acid, SAM, S-adenosylmethionine, THF, tetrahydrofolate, $\boldsymbol{\uparrow}$, increase, $\boldsymbol{\Downarrow}$, decrease.

For measuring the arginase activity in C. elegans, some enzymatic properties of arginase were determined using a homogenate of $\mathrm{B}_{12}$-deficient worms (Supplementary Figure S2). Most arginases have the highest activity in alkaline $\mathrm{pH}$ ranges and require $\mathrm{Mn}$ (II) ion or $\mathrm{Co}$ (II) ion as a cofactor [24]. Similarly, arginase in the worms showed the highest activity at $\mathrm{pH} 8.0$ and absolutely required $\mathrm{Mn}$ (II) ion. Even though arginase activity (approximately $0.4-0.8 \mathrm{pmol} / \mathrm{min} / \mathrm{mg}$ protein) was detected in a homogenate of $C$. elegans, worm enzyme activity was significantly lower than that of human liver (5 $\mu \mathrm{mol} / \mathrm{min} / \mathrm{mg}$ protein) and red blood cells $(0.05 \mu \mathrm{mol} / \mathrm{min} / \mathrm{mg}$ protein) [25]. These results and perspectives indicated that $C$. elegans has the arginase with weak function. However, the gene product of T21F4.1 could not be characterized as arginase in detail because of the unsuccessful cloning and overexpression of the T21F4.1 gene. Peroxisome proliferator activated-receptor (PPAR) $\alpha$ is considered to possess the regulation function of the expression of genes involved in $\beta$-oxidation in fatty acids. 
Ahmad et al. [26] found that the protein expression of arginase 1 increases through the PPAR signaling pathway in $\mathrm{B}_{12}$-deficient rats. The mRNA level of T21F4.1 may increase due to the activation of PPAR signaling pathway by lipid metabolic disorder caused by $\mathrm{B}_{12}$ deficiency. When $\mathrm{B}_{12}$-deficient worms were grown in NOHA-treated conditions, ornithine was decreased to control level with a decrease in the arginase activity (Figure $4 \mathrm{a}, \mathrm{b}$ ). These results suggested that the accumulation of ornithine during $\mathrm{B}_{12}$ deficiency was a result of the increase in arginase activity. In addition, urea is well-known as an antioxidant in the body [27]. Urea formed by the action of arginase may function as an antioxidant because $B_{12}$ deficiency induced severe oxidative stress in C. elegans.

As described above, the increased arginase activity in C. elegans during $B_{12}$ deficiency resulted in increased ornithine, which is a precursor amino acid of polyamines. The reduced activity of $\mathrm{B}_{12}$-dependent MS by $\mathrm{B}_{12}$ deficiency [8] further decreased cellular SAM levels (Figure 5a), leading to a significant decrease of Spd (Figure 6b) in C. elegans. A significant reduction in the cardiac and serum SAM/SAH ratio has been reported in mammals during $B_{12}$ deficiency $[28,29]$ likewise $B_{12}$-deficient worms. In addition, Spd reportedly stimulated $B_{12}$-dependent MS activity [30], suggesting that reduced Spd may further decrease $\mathrm{B}_{12}$-dependent MS activity, thus increasing homocysteine [8] and leading to the further development of oxidative damage [20]. The biosynthesis of Put and Spd is highly regulated by two key enzymes, namely, ornithine decarboxylase (ODC, EC.4.1.1.17) and SAMDC (EC.4.1.1.50), are strongly regulated by feedback mechanisms at several levels, including transcriptional, translational, and post-translational [31]. In particular, ODC activity reportedly increased in murine L1210 leukemia cells [32] and in the spinal cords of totally gastrectomized rats [33] by the decrease in SAM. Spermine, which is a polyamine, was not detected in C. elegans in this study. Caenorhabditis elegans are not believed to contain spermine because no homologous gene of spermine synthase (EC. 2.5.1.22) has been found [34]. In general, odc-1 and smd-1 gene expressions were strictly regulated by substrates and productions [31]. From these results and suggestions, it was difficult to interpret the response of changes of odc- 1 and smd-1 gene expression in the case of C. elegans not having spermine.

Polyamines play multiple roles in cell growth and death, including aging, neurodegenerative diseases, and metabolic disorders [35]. In particular, Spd has shown life-prolonging effects in various organisms, including in mammals and C. elegans. Indeed, Eisenberg et al. [36] have demonstrated that the administration of exogenous Spd significantly extends lifespan through epigenetic modifications, the inducement of autophagy, and a decline in necrosis using yeast, flies, $C$. elegans, and human immune cells as aging models. Remaining factors underlying the reduced lifespan observed during $B_{12}$ deficiency may be due to inhibition of the TCA cycle, which would disrupt normal energy production, leading to oxidative damage in various cellular components, and reduced methylation reactions involving cellular compounds $[8,20]$.

\section{Conclusions}

Collectively, our novel findings indicated that $\mathrm{B}_{12}$ deficiency induced both significant increases in ornithine and decreases in Spd, due to the reduction of SAM and/or the SAM/SAH ratio through decreased $\mathrm{B}_{12}$-dependent MS activity. Although such a phenomenon has not been reported in $\mathrm{B}_{12}$-deficient mammals, evidence exists that changes in polyamine levels are associated with aging and disease [37]. Thus, polyamines may prove to be key compounds underlying the symptoms of various health conditions (megaloblastic anemia, developmental disorders, growth retardation, and neuropathy) caused by $\mathrm{B}_{12}$ deficiency. To further clarify the accurate functions of polyamines associated with the symptoms of $B_{12}$ deficiency in mammals, further studies are warranted.

Supplementary Materials: The following are available online at http://www.mdpi.com/2218-1989/9/9/192/s1, Figure S1: HPLC analysis of polyamines (putrescine and spermidine) found in worms grown in vitamin $\mathrm{B}_{12}$-supplemented and vitamin $\mathrm{B}_{12}$-deficient conditions, Figure S2: Some properties of Caenorhabditis elegans arginase, Figure S3: Amino acid analysis of worms grown in vitamin $\mathrm{B}_{12}$-supplemented and vitamin $\mathrm{B}_{12}$-deficient conditions. 
Author Contributions: Conceptualization, T.B. and F.W.; methodology, T.B.; validation, T.B., K.O. and N.O.; formal analysis, T.B., K.O. and F.W.; investigation, T.B., N.O. and K.O.; resources, T.K.; data curation, T.B. and K.O.; writing—original draft preparation, T.B.; writing—review and editing, Y.Y., J.A., T.K. and F.W.; visualization, T.B. and F.W.; supervision, J.A., T.K. and F.W.; project administration, T.B. and F.W.; funding acquisition, T.B. and F.W.

Funding: This research was funded by URAKAMI Foundation (T.B.) and JSPS KAKENHI, grant numbers 14J05387 (T.B), 17K15270 (T.B.), and 20580132 (F.W.).

Conflicts of Interest: The authors declare no conflict of interest.

\section{References}

1. Watanabe, F.; Bito, T. Vitamin $\mathrm{B}_{12}$ sources and microbial interaction. Exp. Biol. Med. 2017, 243, 148-158. [CrossRef] [PubMed]

2. Watanabe, F.; Yabuta, Y.; Bito, T.; Teng, F. Vitamin B 12 -containing plant food sources for vegetarians. Nutrients 2014, 6, 1861-1873. [CrossRef] [PubMed]

3. Fowler, B. Genetic defects of folate and cobalamin metabolism. Eur. J. Pediatr. 1998, 157, S60-S66. [CrossRef] [PubMed]

4. Banerjee, R. Radical peregrinations catalyzed by coenzyme $\mathrm{B}_{12}$-dependent enzymes. Biochemistry 2001, 40, 6191-6198. [CrossRef] [PubMed]

5. Kennedy, D.G.; Cannavan, A.; Molloy, A.; O'harte, F. Methylmalonyl-CoA mutase (EC 5.4.99.2) and methionine synthetase (EC 2.1.1.13) in the tissues of cobalt-vitamin $B_{12}$ deficient sheep. Br. J. Nutr. 1990, 64, 721-732. [CrossRef] [PubMed]

6. Toyoshima, S.; Watanabe, F.; Saido, H.; Miyatake, K.; Nakano, Y. Methylmalonic acid inhibits respiration in rat liver mitochondria. J. Nutr. 1995, 125, 2846-2850. [CrossRef] [PubMed]

7. Lu, S.C. S-Adenosylmethionine. Int. J. Biochem. Cell Biol. 2000, 32, 391-395. [CrossRef]

8. Bito, T.; Matsunaga, Y.; Yabuta, Y.; Kawano, T.; Watanabe, F. Vitamin $\mathrm{B}_{12}$ deficiency in Caenorhabditis elegans results in loss of fertility, extended life cycle, and reduced lifespan. FEBS Open Bio 2013, 3, 112-117. [CrossRef]

9. Ebara, S.; Toyoshime, S.; Matsumura, T.; Adachi, S.; Takenaka, S.; Yamaji, R.; Watanabe, F.; Miyatake, K.; Inui, H.; Nakano, Y. Cobalamin deficiency results in severe metabolic disorder of serine and threonine in rats. Biochim. Biophys. Acta 2001, 1568, 111-117. [CrossRef]

10. Li, H.; Ren, C.; Shi, J.; Hang, X.; Zhang, F.; Gao, Y.; Wu, Y.; Xu, L.; Chen, C.; Zhang, C. A proteomic view of Caenorhabditis elegans caused by short-term hypoxic stress. Proteome Sci. 2010, 8, 49-62. [CrossRef]

11. Brenner, S. The genetics of Caenorhabditis elegans. Genetics 1974, 77, 71-94. [PubMed]

12. Kvannes, J.; Flatmark, T. Rapid and sensitive assay of ornithine decarboxylase activity by high-performance liquid chromatography of the o-phthalaldehyde derivative of putrescine. J. Chromatogr. B Biomed. Sci. Appl. 1987, 419, 291-295. [CrossRef]

13. Wang, W.; Kramer, P.M.; Yang, S.; Pereira, M.A.; Tao, L. Reversed-phase high-performance liquid chromatography procedure for the simultaneous determination of S-adenosyl-L-methionine and S-adenosyl-L-homocysteine in mouse liver and the effect of methionine on their contractions. J. Chromatogr. B Biomed. Sci. Appl. 2001, 762, 59-65. [CrossRef]

14. Yamamoto, A.; Shim, I.S.; Fujiwara, S.; Yonezawa, T.; Utsui, K. Effect of difference in nitrogen media on salt-stress response and contents of nitrogen compounds in rice seeding. Soil Sci. Plant Nutr. 2004, 50, 85-93. [CrossRef]

15. Apfeld, J.; Kenyon, C. Cell nonautonomy of C. elegans daf-2 function in the regulation of diapause and life span. Cell 1998, 95, 199-210. [CrossRef]

16. Bradford, M.M. A rapid and sensitive method for the quantitation of microgram quantities of protein utilizing the principle of protein-dye binding. Anal. Biochem. 1976, 72, 248-254. [CrossRef]

17. Daniel, D.S.; Iva, G. OrthoList: A compendium of C. elegans genes with human orthologs. PLoS ONE 2011, 6, e20085. [CrossRef]

18. Wu, G.; Morris, S.M., Jr. Arginine metabolism: Nitric oxide and beyond. Biochem. J. 1998, 336, 1-17. [CrossRef]

19. Berkowitz, D.E.; White, R.; Li, D.; Minhas, K.M.; Cernetich, A.; Kim, S.; Burke, S.; Shoukas, A.A.; Nyhan, D.; Champion, H.C.; et al. Arginase reciprocally regulates nitric oxide synthase activity and contributes to endothelial dysfunction in aging blood vessels. Circulation 2003, 108, 2000-2006. [CrossRef] 
20. Bito, T.; Misaki, T.; Yabuta, Y.; Ishikawa, T.; Kawano, T.; Watanabe, F. Vitamin $B_{12}$ deficiency results in severe oxidative stress, leading to memory retention impairment in Caenorhabditis elegans. Redox Biol. 2017, 11, 21-29. [CrossRef]

21. Chandra, S.; Romero, M.J.; Shatanawi, A.; Alkilany, A.M.; Caldwell, R.B.; Caldwell, R.W. Oxidative species increase arginase activity in endothelial cells through the RhoA/Rho kinase pathway. Br. J. Pharmacol. 2012, 165, 506-519. [CrossRef] [PubMed]

22. Butler, J.A.; Mishur, R.J.; Bokov, A.F.; Hakala, K.W.; Weintraub, S.T.; Rea, S.L. Profiling the anaerobic response of C. elegans using GC-MS. PLoS ONE 2012, 7, e46140. [CrossRef] [PubMed]

23. Wright, D.J. Elimination of nitrogenous compounds by Panagrellus redivivus, goodey, 1945 (Nematoda: Cephalobidae). Comp. Biochem. Physiol. Part B Comp. Biochem. 1975, 52, 247-253. [CrossRef]

24. Ash, D.E. Structure and function of Arginases. J. Nutr. 2004, 134, 2760S-2764S. [CrossRef] [PubMed]

25. Sasaki, A.; Doi, S.; Mizutani, S.; Azuma, H. Roles of accumulated endogenous nitric oxide synthase inhibitors, enhanced arginase activity, and attenuated nitric oxide synthase activity in endothelial cells for pulmonary hypertention in rats. Am. J. Physiol. Lung Cell Physiol. 2007, 292, L1480-L1487. [CrossRef] [PubMed]

26. Ahmad, S.; Kumar, K.A.; Basak, T.; Bhardwaj, G.; Yadav, D.K.; Lalitha, A.; Chandak, G.R.; Raghunath, M.; Chandak, G.R. PPAR signaling pathway is a key modulator of liver proteome in pups born to vitamin $\mathrm{B}_{12}$ deficient rats. J. Proteomics. 2013, 91, 297-308. [CrossRef] [PubMed]

27. Wang, X.; Wu, L.; Aouffen, M.; Mateescu, M.A.; Nadeau, R.; Wang, R. Novel cardiac protective effects of urea: From shark to rat. Br. J. Pharmacol. 1999, 128, 1477-1484. [CrossRef] [PubMed]

28. Guerra-Shinohara, E.M.; Morita, O.E.; Pagliusi, R.A.; Blaia-d' Avila, V.L.; Allen, R.H.; Stabler, S.P. Elevated serum S-adenosylhomocysteine in cobalamin-deficient megaloblastic anemia. Metabolism 2007, 56, 339-347. [CrossRef] [PubMed]

29. Taban-Shomal, O.; Kilter, H.; Wagner, A.; Schorr, H.; Umanskaya, N.; Hübner, U.; Böhm, M.; Herrmann, W.; Herrmann, M. The cardiac effects of prolonged vitamin $\mathrm{B}_{12}$ and folate deficiency in rats. Cardiovasc. Toxicol. 2009, 9, 95-102. [CrossRef]

30. Kenyon, S.H.; Nicolaou, A.; Ast, T.; Gibbons, W.A. Stimulation in vitro of vitamin $\mathrm{B}_{12}$-dependent methionine synthase by polyamines. Biochem. J. 1996, 316, 661-665. [CrossRef]

31. Persson, L. Polyamine homoeostasis. Essays Biochem. 2009, 46, 11-24. [CrossRef] [PubMed]

32. Kramer, D.L.; Sufrin, J.R.; Porter, C.W. Relative effects of $S$-adenosylmethionine depletion on nucleic acid methylation and polyamine biosynthesis. Biochem. J. 1987, 247, 259-265. [CrossRef] [PubMed]

33. Scalabrino, G.; Monzio-Compagnoni, B.; Ferioli, M.E.; Lorenzini, E.C.; Chiodini, E.; Candiani, R. Subacute combined degeneration and induction of ornithine decarboxylase in spinal cords of totally gastrectomized rats. Lab. Investig. 1990, 62, 297-304. [PubMed]

34. Pegg, A.E.; Michael, A.J. Spermine synthase. Cell Mol. Life Sci. 2010, 67, 113-121. [CrossRef] [PubMed]

35. Miller-Fleming, L.; Olin-Sandoval, V.; Campbell, K.; Ralser, M. Remaining mysteries of molecular biology: The role of polyamines in the cell. J. Mol. Biol. 2015, 427, 3389-3406. [CrossRef] [PubMed]

36. Eisenberg, T.; Knauer, H.; Schauer, A.; Büttner, S.; Ruckenstuhl, C.; Carmona-Gutierrez, D.; Ring, J.; Schroeder, S.; Magnes, C.; Antonacci, L.; et al. Induction of autophagy by spermidine promotes longevity. Nat. Cell Biol. 2009, 11, 1305-1314. [CrossRef] [PubMed]

37. Handa, A.K.; Tahira, F.; Mattoo, A.K. Polyamines: Bio-molecules with diverse functions in plant and human health and disease. Front Chem. 2018, 6, 10. [CrossRef]

(C) 2019 by the authors. Licensee MDPI, Basel, Switzerland. This article is an open access article distributed under the terms and conditions of the Creative Commons Attribution (CC BY) license (http://creativecommons.org/licenses/by/4.0/). 